\title{
Analysis on risk factors for neck shortening after internal fixation for Pauwels II femoral neck fracture in young patients
}

Fulong Zhao

Beijing Luhe Hospital

Lijuan Guo

Chinese Emergency General Hospital

xuefei wang ( $\sim 1425496527 @ q q . c o m$ )

Beijing Luhe Hospital https://orcid.org/0000-0003-3976-4908

Yakui Zhang

Beijing Luhe Hospital

\section{Research}

Keywords: Young patients, Femoral neck fracture, Internal fixation, Neck shortening, Risk factors

Posted Date: January 5th, 2021

DOl: https://doi.org/10.21203/rs.3.rs-29466/v2

License: (a) (i) This work is licensed under a Creative Commons Attribution 4.0 International License. Read Full License 


\section{Abstract}

Background: Femoral neck shortening can occur in young patients receiving internal fixation for Pauwels type II femoral neck fracture. The risk factors for neck shortening, which can affect hip function, are not clear. This study aimed to retrospectively identify risk factors for neck shortening after internal fixation with parallel partially threaded cannulated cancellous screws (FPTCS) for Pauwels type II femoral neck fracture in relatively young patients. Methods: Clinical data from 122 cases with Pauwels type II femoral neck fracture from February 2014 to February 2019 were reviewed and analyzed, and causes of neck shortening were statistically analyzed. And the chi-squared test or Fisher's exact test was used to compare indicators. Multivariate analysis was conducted with non-conditional logistic regression analysis.

Results: Statistically significant differences were found in age, sex, BMD, BMI, fracture type, posterior medial cortex comminution, and reduction quality between patients with femoral neck shortening and those without femoral neck shortening. Logistic regression analysis showed that fracture type, posterior medial cortex comminution, and reduction quality were the main risk factors for neck shortening.

Conclusion $\triangle$ Fracture type, posterior medial cortex comminution, and reduction quality can be used as important reference indexes to predict the possibility of neck shortening after internal fixation with FPTCS for Pauwels type II femoral neck fracture in young patients.BMD and BMI may be also risk factors.

\section{Background}

Femoral neck fracture is a common injury in orthopedics. Young patients account for $2-3 \%$ of cases[1], and 6000 young people have femoral neck fracture every year [2]. The fracture of the femoral neck in young patients is often caused by high-energy trauma, the increasing incidence of which has increased the incidence of femoral neck fracture in young patients. The treatment is anatomical reduction and internal fixation as soon as possible[3,4].The failure rate of treatment of femoral neck fracture in young adults is high. This is a challenging problem because there are many treatment options and consensus on the best treatment has been difficult to reach [5]. Multiple cancellous screws or sliding hip screws are still the most commonly used internal fixation implants [6,7].Young patients are commonly treated by fracture fixation with FPTCS [8-11], while fully threaded screws are rarely used [12].

Pauwels type II fracture is described as an unstable fracture: shear stress at the fracture end may have an adverse effect on fracture healing, but internal fixation can reduce shear stress and promote fracture healing[13].However, in treatment of femoral neck fracture in the young, shortening of the femoral neck can occur after fixation with multiple cancellous screws, and this affects the function of the hip joint $[14,15]$. This has led to more research on the incidence and resolution of this complication $[16,17]$. Other studies have focused on the complications of this operation [18-21]. So far, few studies have attempted to determine the risk factors for shortening by using multivariate regression analysis. 
In this retrospective study, fixations for Pauwels type II fracture were performed based on the inverted triangle configuration. An inverted triangle screw configuration has been recommended for internal fixation in femoral neck fractures, because this configuration has provided better biomechanical stability compared to other configurations [22-24].Based on femur anatomy, the cross section of the femur neck is similar to an inverted triangle configuration. Therefore, our screw configuration was demonstrated to provide clear mechanical advantages in previous studies [25,26]. However, some studies indicated that different operative protocols for femoral neck fractures had different effects on the mechanical features [27-29].

Fully understanding the risk factors for neck shortening after internal FPTCS for young Pauwels type II femoral neck fracture is of great importance in improving the safety of the operation and ensuring its therapeutic effect. In this study we retrospectively analyzed the main causes of neck shortening after internal FPTCS in young patients with Pauwels type II femoral neck fracture in order to identify risk factors, and tried to determine the effects of these factors on postoperative neck shortening.

\section{Patients And Samples}

\section{Criteria for inclusion and exclusion of patients}

Criteria for patient inclusion in the study were age 59 years or younger, Pauwels type II femoral neck fracture confirmed by X-ray and CT, capacity for basic self-care, normal cognition, and the patient's agreement to participate in the study. Exclusion criteria were pathological fracture, multiple fracture, and mental illness.

\section{Research objectives}

The clinical data from 122 young patients with femoral neck fractures treated in our hospital from February 2014 to February 2019 were retrospectively analyzed. The study included 65 males $(53.28 \%)$ and $57 f$ females $(46.72 \%)$, and the average age was $40.79 \pm 19.63$ years (range, $18-$ 59 years).According to the Garden classification, there were 14 cases with type I, 25 with type II, 45 with type III, and 38 of type IV. Conditions before the patient's injury were fully understood. Relevant examinations were performed in preoperative assessment. All operations were performed by the same group of surgeons using three FPTCS. Reduction quality was assessed using the method of Lowell [30].

\section{Surgical methods}

The patient was placed on a traction bed and their limbs were fixed. C-arm X-ray was used to identify whether fracture reduction was satisfactory or not in the anteroposterior (A/P) and lateral views. Based

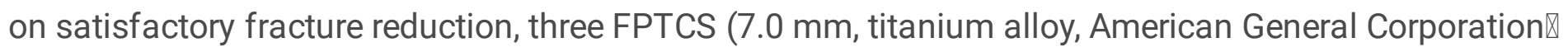


USA), were implanted in the femoral neck in an inverted triangle configuration: The inferior screw was placed on the coronal axis of the proximal femur, close to the femoral calcar; the superior screw was placed in the anteror superior cortex of the femoral neck; and the third screw was placed in the posterior cortex for support (Fig.1).All three screws were placed under the subchondral bone of the femoral head. The quality of fracture reduction was judged by postoperative examination of the hip joint in the A/P and lateral views.

\section{Research methods}

The method used to measure neck shortening in this study is consistent with previous studies[17,31]. According to whether it occurred, the 122 young patients with femoral neck fractures were divided into a neck shortening group (37 cases) and a non-neck shortening group (85cases). In this study, we found that, in the neck shortening group, the femoral neck was shortened by $5-9 \mathrm{~mm}$, with an average of $7 \mathrm{~mm}$. Previous studies have shown that, when the femoral neck is shortened by more than $5 \mathrm{~mm}$, it had a negative effect on the quality of life $[14,20,32]$. Observed indexes in the study included patient's age, sex, BMD, body mass index (BMI)[33], fracture type, posterior medial cortex comminution, reduction quality, surgical time, time to weight bearing, and time of hospitalization, which were entered into the database. The average value of each index was recorded.

\section{Statistical methods}

All data analyses were conducted using SPSS 22.0 statistical software. The occurrence of neck shortening was considered as a dependent variable, while the observed indexes were used as independent variables. Data are reported as the mean \pm standard deviation (SD), and were compared using the chi-squared test or Fisher's exact test. Non-conditional logistic regression was performed to identify risk factors for neck shortening. The difference in the effective rate was considered statistically significant at $p<0.05$.

\section{Results}

\section{Neck fracture healing rate and Harris score inthe neck shortening group and non-shortening group}

There were 37(30.33\%) cases in the shortening group and 85 cases in the non-shortening group. In the shortening group, 33 cases (89.19\%) healed, and the average Harris score was $79 \pm 13$. In the nonshortening group, 74 cases $(87.06 \%)$ healed, and the mean Harris score was $87 \pm 16$. The differences in the fracture healing rate and the mean Harris score were not statistically significant ( $p>0.05$ for each). The total incidence of nonunion was $12.29 \%$ (15/122):10.81\% (4/37) in the shortening group, and $12.94 \%$ $(11 / 85)$ in the non-shortening group. (Table 1$)$ 
Table 1 - Comparison of healing rate between two groups.

\begin{tabular}{lllll}
\hline & Shortening & Non-shortening & $\boldsymbol{\chi}^{2}$ & $\boldsymbol{p}$ \\
\hline Healing rate & $89.19 \%(33 / 37)$ & $87.06 \%(74 / 85)$ & 0.026 & 0.871 \\
Harris score & $79 \pm 13$ & $87 \pm 16$ & 0.386 & 0.534 \\
\hline
\end{tabular}

\section{Factors influencing the occurrence of neck shortening}

There were statistically significant differences in variables between the femoral neck shortening group and non-shortening group, including patient age, sex, BMD, BMI, fracture type, posterior medial cortex comminution, and reduction quality. There were no statistically significant differences between the two groups with respect to surgical time, time to weight bearing, or hospitalization time (Table 2).

Table 2 - Comparison of patient characteristics between the two groups.

\begin{tabular}{|c|c|c|c|c|c|c|}
\hline Factors & & $\mathrm{n}$ & shortening group & non-shortening group & $\chi^{2}$ & $p$ \\
\hline$\overline{\text { Age(y) }}$ & $\begin{array}{l}18-44 \\
45-59\end{array}$ & $\begin{array}{l}65 \\
57\end{array}$ & 14 & 51 & 5.086 & 0.024 \\
\hline Sex & Male & $\begin{array}{l}83 \\
39\end{array}$ & $\begin{array}{l}23 \\
30\end{array}$ & 53 & 4.157 & 0.041 \\
\hline BMD & $\begin{array}{l}\text { Female } \\
\mathrm{T}>-2.5 \\
\mathrm{~T} \leq-2.5\end{array}$ & $\begin{array}{l}39 \\
75 \\
47\end{array}$ & $\begin{array}{l}7 \\
17 \\
20\end{array}$ & $\begin{array}{l}32 \\
58 \\
27\end{array}$ & 5.408 & 0.020 \\
\hline $\operatorname{BMI}\left(\mathrm{kg} / \mathrm{m}^{2}\right)$ & $\begin{array}{l}<24.0 \\
24.0 \leq \mathrm{BMI}<28.0 \\
\geq 28.0\end{array}$ & $\begin{array}{l}60 \\
44 \\
18\end{array}$ & $\begin{array}{l}12 \\
15 \\
10\end{array}$ & $\begin{array}{r}48 \\
29 \\
8\end{array}$ & 8.745 & 0.012 \\
\hline Fracture type & $\begin{array}{l}\text { Type I, II } \\
\text { Type III, IV }\end{array}$ & $\begin{array}{l}33 \\
89\end{array}$ & $\begin{array}{l}19 \\
18\end{array}$ & $\begin{array}{l}14 \\
71\end{array}$ & 15.895 & 0.000 \\
\hline $\begin{array}{l}\text { Posterior medial cortex } \\
\text { comminution }\end{array}$ & $\begin{array}{l}\text { Yes } \\
\text { No }\end{array}$ & $\begin{array}{l}82 \\
40\end{array}$ & $\begin{array}{c}32 \\
5\end{array}$ & $\begin{array}{l}50 \\
35\end{array}$ & 8.952 & 0.002 \\
\hline Reduction quality & $\begin{array}{l}\text { Grade I, II } \\
\text { Grade III, IV }\end{array}$ & $\begin{array}{l}77 \\
45\end{array}$ & $\begin{array}{l}15 \\
22\end{array}$ & $\begin{array}{l}62 \\
23\end{array}$ & 11.625 & 0.000 \\
\hline Surgical time & $\begin{array}{l}\leq 24 \mathrm{hr} \\
>24 \mathrm{hr}\end{array}$ & $\begin{array}{l}79 \\
43\end{array}$ & $\begin{array}{l}23 \\
14\end{array}$ & $\begin{array}{l}56 \\
29\end{array}$ & 0.156 & 0.692 \\
\hline Time to weight bearing & $\begin{array}{l}\leq 2 \text { months } \\
>2 \text { months }\end{array}$ & $\begin{array}{l}91 \\
31\end{array}$ & $\begin{array}{l}27 \\
10\end{array}$ & $\begin{array}{l}64 \\
21\end{array}$ & 0.073 & 0.787 \\
\hline Hospitalization time & $\begin{array}{l}\leq 1 \text { week } \\
>1 \text { week }\end{array}$ & $\begin{array}{l}75 \\
47 \\
\end{array}$ & $\begin{array}{l}22 \\
15 \\
\end{array}$ & $\begin{array}{l}53 \\
32 \\
\end{array}$ & 0.091 & 0.762 \\
\hline
\end{tabular}

\section{Non-conditional logistic regression analysis of factors in fluencing neck shortening}

Between-group differences in the above seven factors were statistically significant $(p<0.05)$ by the chisquared test. These factors were further analyzed using logistic regression. The results showed that BMD (Ts-2.5), BMI ( $\left.\geq 28.0 \mathrm{~kg} / \mathrm{m}^{2}\right)$, fracture type (type III, IV), posterior medial cortex comminution(Yes), and reduction quality (Grade III, IV) had an impact on the occurrence of neck shortening(Table 3).

Table 3 -Non-conditional logistic regression analysis of factors influencing femoral neck shortening after fixation with partially threaded cannulated screws in young patients. 


\begin{tabular}{|c|c|c|c|c|}
\hline Influencing Factors & B & $\operatorname{Exp}(\mathrm{B})$ & $95 \% C I$ & $p$ \\
\hline Age (45-59 years) & 1.141 & 0.686 & $(0.85-13.59)$ & 0.104 \\
\hline & & & & 0.282 \\
\hline & & 10 & & 0.007 \\
\hline & 2. & & 1) & 04 \\
\hline & 3.1 & & 7) & 0.000 \\
\hline Pos & 5.614 & & 41.17) & 0.000 \\
\hline $\operatorname{Rec}$ & 2.056 & 14.94 & $1-28.85)$ & 0.000 \\
\hline
\end{tabular}

$C l$,confidence interval

\section{Discussion}

Femoral neck fracture is a common fracture. Previous studies have shown that good closed reduction and internal fixation using cannulated screws in the treatment of femoral neck fracture is efficacious[34,35]. However, neck shortening in the course of treatment is still worthy of attention. A considerable proportion of patients present this phenomenon on follow-up imaging, which is less concerned. Its incidence in this study was $30.33 \%$ (37/122), very similar to that in a previous study [17].The total incidence of nonunion was $12.29 \%$, in accord with previous studies[36,37].

Here, we retrospectively studied data from 122 young patients who had Pauwels type II femoral neck fractures treated using FPTCS and analyzed possible factors influencing neck shortening. Univariate analysis showed that patient age, sex, BMD, BMI, fracture type, and reduction quality were risk factors for neck shortening. Age and BMD were closely related to the occurrence of neck shortening. With increasing age, BMD may decline, and it is clear that bone quality may determine the probability of femoral neck fracture [38].Reduction of the axial anti-compression strength of the femoral neck leads to its shortening. Sex is also an important influencing factor. Compared with men, women have thinner bone cortex and lower bone density. After menopause, estrogen decreases rapidly, which further affect the process of fracture repair[39]. BMI also increases the risk of neck shortening after fracture[40]. Increased BMI may directly increase the axial pressure on the fracture end, leading to neck shortening. Therefore, for patients with these risk factors, a comprehensive preoperative evaluation is essential, although this complication may result from a combination of these factors.

Non-conditional logistic regression analysis showed that fracture type (Garden III, IV) and reduction quality (Grade III, IV) were the main causes of postoperative neck shortening. Higher fracture type, posterior medial cortex comminution, and lower reduction quality could indicate a greater risk of postoperative neck shortening in young patients who had Pauwels type II femoral neck fractures. Therefore, more attention should be paid to these three indicators during clinical observations. We found that fracture type (Garden III, IV) may increase the likelihood of neck shortening, as previously reported $[9,18]$. Garden type III and IV fractures are unstable and often accompanied by comminution or posterior medial bone cortical defects[41].Comminuted fractures increase bone absorption after surgery and are more likely to produce neck shortening after healing. Destruction of the posterior medial cortex often leads to a lowering of both the quality of reduction and resistance to axial loading, and results in neck shortening, even when complete anatomical reduction is achieved in the 
operation[42]. Garden's Alignment Index is commonly used to evaluate reduction quality. When the evaluated fracture reduction quality fails to meet the standard of anatomical reduction, the probability of postoperative neck shortening is greatly increased[18]. It is possible that the stress on the fracture's broken end is not uniform, leading to collapse at the fracture site, with consequent neck shortening.

In this study, a univariate analysis showed that patient age, sex, BMD, BMI, fracture type, and reduction quality were risk factors for femoral neck shortening. Importantly, a multifactor analysis showed that, in the shortening group, the main causes of neck shortening were the fracture type (Garden III, IV), reduction quality (Grade III, IV), and the posterior medial cortex comminution; additionally, secondary causes might be BMD $(T \leq-2.5)$ and $\mathrm{BMI}\left(\geq 28.0 \mathrm{~kg} / \mathrm{m}^{2}\right)$. These results indicated that the Harris score in the shortened group was lower than that in the non-shortened group. That finding suggested that neck shortening would result in reduced hip function, which was mainly manifested as claudication and poor abduction strength [43]. A potential mechanism for these manifestations could be that neck shortening might have affected the arm of the abductor muscle, which reduced the ability of the hip joint to maintain a stable gait and pelvic balance [44]. Consequently, patients had to increase the abductor muscle strength to compensate when walking, which resulted in walking claudication. In future, it would be interesting to explore whether there might be some quantitative relationship between the degree of femoral neck shortening and the hip function score.

Although early mobilization following young femoral neck fracture surgery is of superior importance, to date, there is no unified postoperative rehabilitation protocol. In this study, the postoperative weightbearing program was determined by the physician in charge, and it depended on many factors, including age, sex, BMD, BMI, fracture type, posterior medial cortex comminution, and reduction quality. In general, partial weight bearing activities, with the use of an assistive device, were allowed as soon as patients could tolerate them. In patients with the risk factors mentioned above, partial weight-bearing was delayed until 8 weeks after surgery. During those 8 weeks, the patient performed functional exercises for the affected limb, without bearing weight.

This study has some limitations. First, our results were based on a small number of patients. We still did not accurately predict whether neck shortening was related to the healing rate of the femoral neck fracture. Second, we did not include patients with Pauwels type I and III fractures. Third, because there are few studies on neck shortening and all methods for measuring neck shortening are still in their initial stages, more accurate methods of measurement need to be further explored.

To reduce the effect of postoperative neck shortening on hip function, we have changed our treatment of femoral neck fractures by using fully threaded screws or a femoral neck system (FNS), instead of FPTCS. Currently, a clinical follow up is ongoing to evaluate the degree of postoperative neck shortening and its effects on hip function, when treated with fully threaded screws or FNS. Those findings will be reported in future studies. 
In conclusion, Our results support the use of fracture type, the presence of comminution of the posterior medial cortex, and reduction quality as important reference indexes to predict the possibility of neck shortening after internal fixation with FPTCS for Pauwels type II femoral neck fracture in young patients. $\mathrm{BMD}$ and BMI may also be risk factors. The results also suggest that fracture type, posterior medial cortex comminution, and reduction quality might be useful for evaluating postoperative neck shortening.

\section{Declarations}

\section{Ethics approval and consent to participate}

Written informed consent was obtained from patients under a protocol approved by the Ethics Committee of Beijing Luhe Hospital affiliated to Capital Medical University.

\section{Consent for publication}

Not applicable.

\section{Availability of data and materials}

All data analyzed during this study are included in this published article.

\section{Competing interests}

The authors declare that they have no competing interests.

\section{Funding}

No fund was received.

\section{Authors' contributions}

FL $Z$ and XF W designed and initiated the study. FL Z and YK Z collected data. LJ G and XF W performed the statistical analysis. FL $Z$ and $L J G$ wrote the article.

\section{Acknowledgements}

Not applicable

\section{References}

1. Zetterberg C, Elmerson S, Andersson GB. Epidemiology of hip fractures in Göteborg, Sweden, 19401983.Clin Orthop Relat Res. 1984 ;(191):43-52.

2. Court-Brown C, Koval K, Bucholz R, Heckman J, Court-Brown C, editors. 6th ed. Philadelphia PA: Lippincott Williams \& Wilkins; 2006. The Epidemiology of Fractures In: Rockwood and Green's Fractures in Adults; pp. 95-143.

3. Khan AQ, Khan MS, Sherwani MK, Agarwal R. Role of valgus osteotomy and fixation with dynamic hip screw and 120 degrees double anglebarrel plate in the management of neglected and ununited femoral neck fracture in young patients. J Orthop Traumatol. 2009; 10(2):71-8.

4. Ribeiro TA, Premaor MO, Larangeira JA, Brito LG, Luft M, Guterres LW, Monticielo OA. Predictors of hip fracture mortality at a general hospital in South Brazil: an unacceptable surgicaldelay. Clinics (Sao Paulo). 2014; 69(4):253-8. 
5. Luttrell K, Beltran M, Collinge CA. Preoperative decision making in the treatment of high-angle "vertical" femoral neck fractures in young adult patients. An expert opinion survey of the Orthopaedic Trauma Association's (OTA) membership. J Orthop Trauma. 2014; 28(9): e221-5.

6. Parker MJ. The management of intracapsular fractures of the proximal femur. J Bone Joint Surg Br. 2000; 82(7):937-41.

7. Parker MJ, Stockton G. Internal fixation implants for intracapsular proximal femoral fractures in adults. Cochrane Database Syst Rev. 2001; (4):CD001467.

8. Füchtmeier B, Gebhard F, Lenich A. Complications after pertrochanteric fractures. Unfallchirurg. 2011; 114(6):479-84.

9. Huang TW, Hsu WH, Peng KT, Lee CY. Effect of integrity of the posterior cortex in displaced femoral neck fractures on outcome after surgical fixation in young adults.Injury. 2011; 42(2):217-22.

10. Asnis SE, Wanek-Sgaglione L.Intracapsular fractures of the femoral neck. Results of cannulated screw fixation.J Bone Joint Surg Am. 1994; 76(12):1793-803.

11. Parker MJ, Porter KM, Eastwood DM, Schembi Wismayer M, Bernard AA. Intracapsular fractures of the neck of femur. Parallel or crossed garden screws? J Bone Joint Surg Br. 1991;73(5):826-7.

12. Weil YA, Qawasmi F, Liebergall M, Mosheiff R, Khoury A.Use of fully threaded cannulated screws decreases femoral neck shortening after fixation of femoral neck fractures.Arch Orthop Trauma Surg. 2018;138(5):661-7.

13. Bartonícek J.Pauwels' classification of femoral neck fractures: correct interpretation of the original. J Orthop Trauma. 2001; 15(5):358-60.

14. Zlowodzki M, Brink O, Switzer J, Wingerter S, Woodall J Jr, Petrisor BA, Kregor PJ, Bruinsma DR, Bhandari M.The effect of shortening and varus collapse of the femoral neck on function after fixation of intracapsular fracture of the hip: a multi-centre cohort study. J Bone Joint Surg Br. 2008; 90(11):1487-94.

15. Haider T, Schnabel J, Hochpöchler J, Wozasek GE.Femoral shortening does not impair functional outcome after internal fixation of femoral neck fractures in non-geriatric patients.Arch Orthop Trauma Surg. 2018;138(11):1511-7.

16. Lecerf G, Fessy MH, Philippot R, Massin P, Giraud F, Flecher X, Girard J, Mertl P, Marchetti E, Stindel E. Femoral offset: anatomical concept, definition, assessment, implications for preoperative templating and hip arthroplasty. Orthop Traumatol Surg Res. 2009; 95(3):210-9.

17. Zlowodzki M, Ayeni O, Petrisor BA, Bhandari M. Femoral neck shortening after fracture fixation with multiple cancellous screws: incidence and effect on function. J Trauma. 2008; 64(1):163-9.

18. Liu Y, Ai ZS, Shao J, Yang T. Femoral neck shortening after internal fixation. Acta Orthop Traumatol Turc. 2013; 47(6):400-4.

19. Levack AE, Gausden EB, Dvorzhinskiy A, Lorich DG, Helfet DL. Novel Treatment Options for the Surgical Management of Young Femoral Neck Fractures. J Orthop Trauma. 2019;33 Suppl 1:S33-7. 
20. Stockton DJ, Lefaivre KA, Deakin DE, Osterhoff G, Yamada A, Broekhuyse HM, O'Brien PJ, Slobogean GP.Incidence, Magnitude, and Predictors of Shortening in Young Femoral Neck Fractures.J Orthop Trauma. 2015; 29(9):e293-8.

21. Kim JY, Kong GM, Park DH, Kim DY.Multiple cannulated screw fixation of young femoral neck fractures. Pak J Med Sci. 2015; 31(6):1517-20.

22. Ye Y, Hao J, Mauffrey $C$, Hammerberg EM, Stahel PF, Hak DJ. Optimizing stability in femoral neck fracture fixation. Orthopedics. 2015; 38(10): 625-30.

23. Oakey JW, Stover MD, Summers HD, Sartori M, Havey RM, Patwardhan AG. Does screw configuration affect subtrochanteric fracture after femoral neck fixation? Clin Orthop Relat Res. 2006; 443:302-6.

24. Selvan VT, Oakley MJ, Rangan A, Al-Lami MK. Optimum configuration of cannulated hip screws for the fixation of intracapsular hip fractures: a biomechanical study. Injury. 2004; 35(2):136-41.

25. Jiantao Li, Menglin Wang, Jianfeng Zhou, Lin Han, Hao Zhang, Chen Li, Lianting Li, Ming Hao. Optimum Configuration of Cannulated Compression Screws for the Fixation of Unstable Femoral Neck Fractures: Finite Element Analysis Evaluation. Biomed Res Int. 2018; 2018:1271762.

26. Qiuliang Zhu, Bengong Shi, Bin Xu, Jianfeng Yuan . Obtuse triangle screw configuration for optimal internal fixation of femoral neck fracture: an anatomical analysis. Hip International. 2019;29(1):72-6.

27. Li J, Wang M, Zhou J, Zhang H, Li L.Finite element analysis of different screw constructs in the treatment of unstable femoral neck fractures. Injury. 2020; 51(4):995-1003.

28. Samsami S, Saberi S, Sadighi S, Rouhi G. Comparison of Three Fixation Methods for FemoralNeckFracture in Young Adults: Experimental and Numerical Investigations. J Med Biol Eng. 2015; 35(5):566-79.

29. Samsami S, Saberi S, Bagheri N, Rouhi G. Interfragmentary motion assessment for three different fixation techniques of femoralneckfractures in young adults. Biomed Mater Eng. 2016;27(4):389404.

30. Karanicolas PJ, Bhandari M, Walter SD, Heels-Ansdell D, Sanders D,Schemitsch E, Guyatt GH. Interobserver reliability of classification systems to rate the quality of femoral neck fracture reduction.J Orthop Trauma. 2009; 23(6):408-12.

31. Weil YA, Khoury A, Zuaiter I, Safran O, Liebergall M, Mosheiff R.Femoral neck shortening and varus collapse after navigated fixation of intracapsular femoral neck fractures.J Orthop Trauma. 2012; 26(1):19-23.

32. Slobogean GP, Stockton DJ, Zeng BF, Wang D, Ma BT, Pollak AN. Femoral neck shortening in adult patients under the age of 55 years is associated with worse functional outcomes: Analysis of the prospective multi-center study of hip fracture outcomes in China (SHOC). Injury.2017; 48(8):1837-42.

33. Chen C, Lu FC; Department of Disease Control Ministry of Health, PR China. The guidelines for prevention and control of overweight and obesity in Chinese adults. Biomed Environ Sci. 2004; 17 Suppl:1-36. 
34. Henari S, Leonard M, Hamadto M, Cogley D. Review of a single contemporary femoral neck fracture fixation method in young patients. Orthopedics. 2011; 34(3):171.

35. Della Rocca GJ. Gaps and opportunities in the management of the young femoral neck fracture. Injury. 2015; 46(3):515-8.

36. Slobogean GP, Sprague SA, Scott T, Bhandari M. Complications following young femoral neck fractures. Injury. 2015; 46(3):484-91.

37. Gumustas S, Tosun HB, Isyar M, Serbest S, Oznam K, Bulut G. Femur neck fracture in young adults, is it really an urgent surgery indication: retrospective clinical study. Pan Afr Med J. 2018; 30:112.

38. Wendlova J. New approach to probability estimate of femoral neck fracture by fall (Slovak regression model). Bratisl Lek Listy. 2009; 110(10):614-9.

39. Estai MA, Suhaimi F, Das S, Shuid AN, Mohamed Z, Soelaiman IN. Expression of TGF- $\beta 1$ in the blood during fracture repair in an estrogen-deficient rat model. Clinics (Sao Paulo). 2011; 66(12): 2113- 9.

40. Zielinski SM, Keijsers NL, Praet SF, Heetveld MJ, Bhandari M, Wilssens JP, Patka P, Van Lieshout EM; FAITH Trial Investigators. Femoral neck shortening after internal fixation of a femoral neck fracture. Orthopedics. 2013; 36(7): e849-58.

41. 41. Rawall S, Bali K, Upendra B, Garg B, Yadav CS, Jayaswal A. Displaced femoral neck fractures in the young: significance of posterior comminution and raised intracapsular pressure. Arch Orthop Trauma Surg. 2012; 132(1):73-9.

42. 42. Bray TJ. Femoral neck fracture fixation. Clinical decision making. Clin Orthop Relat Res. 1997; (339):20-31.

43. Gupta S, Pal B, New AM. The effects of interfacial conditions and stem length on potential failure mechanisms in the uncemented resurfaced femur. Ann Biomed Eng.2010; 38(6): 2107-20.

44. Alves T, Neal JW, Weinhold PS, et al. Biomechanical Comparison of 3 Possible Fixation Strategies to Resist Femoral Neck Shortening After Fracture. Orthopedics.2010; 16(2): 233-7.

\section{Figures}



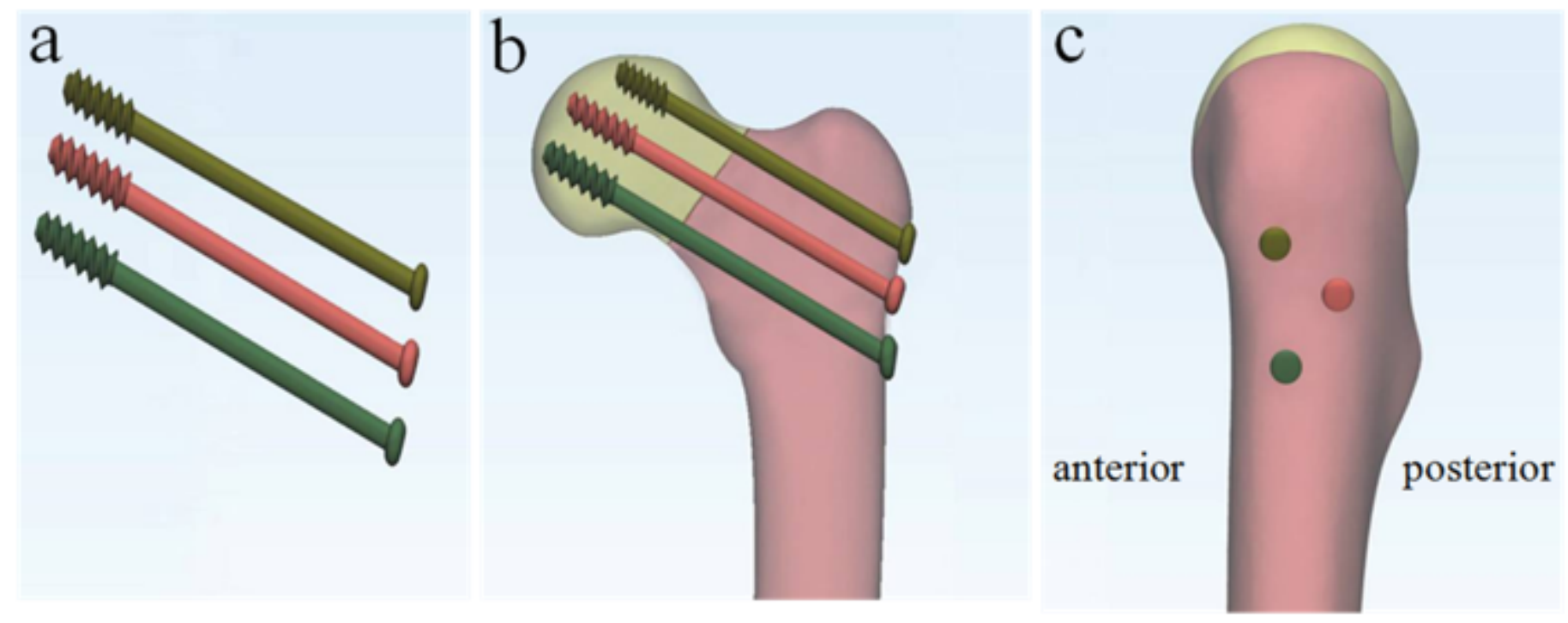

\section{Figure 1}

a Three parallel partially threaded cannulated cancellous screws.b,c Anteroposterior and lateral schematic diagram. 